\title{
Comparison of Vertical Accuracy of Open-Source Global Digital Elevation Models: A Case Study of Adama City, Ethiopia
}

\author{
Hailu Zewde Abili \\ Department Head of Cadastral Surveying and Geomatics Engineering. \\ Institute of Technology - HH Campus, Ambo University, Ethiopia \\ Email: hailuzawde@gmail.com
}

Article History: Received: 11 January 2021; Accepted: 27 February 2021; Published online: 5 April 2021

\begin{abstract}
DEM can be generated from a wide range of sources including land surveys, Photogrammetry, and Remote sensing satellites. SRTM 30m DEM by The Shuttle Radar Topography Mission (SRTM), the Global Digital Elevation Model by Advanced Spaceborne Thermal Emission and Reflectance Radiometer (ASTER GDEM) and a global surface model called ALOS Worldview 3D 30 meter (AW3D30) by Advanced Land Observing Satellite (ALOS) are satellite-based global DEMs opensource DEM datasets. This study aims to assess the vertical accuracy of ASTER GDEM2, SRTM 30m, and ALOS (AW3D30) global DEMs over Ethiopia in the study area-Adama by using DGPS points and available accurate reference DEM data. The method used to evaluate the vertical accuracy of those DEMs ranges from simple visual comparison to relative and absolute comparisons providing quantitative assessment (Statistical) that used the elevation differences between DEM datasets and reference datasets. The result of this assessment showed better accuracy of SRTM 30m DEM (having RMSE of $\pm 4.63 \mathrm{~m}$ ) and closely followed by ALOS (AW3D30) DEM which scored RMSE of $\pm 5.25 \mathrm{~m}$ respectively. ASTER GDEM 2 showed the least accuracy by scoring RMSE of $\pm 11.18 \mathrm{~m}$ in the study area. The second accuracy assessment was done by the analysis of derived products such as slope and drainage networks. This also resulted in a better quality of DEM derived products for SRTM than ALOS DEM and ASTER GDEM.
\end{abstract}

Keywords: Evaluation, Open Source, Global DEMs, RMSE, Vertical accuracy

\section{Introduction}

DEMs can be generated using different techniques such as airborne and satellite-borne stereoscopic photogrammetry, RADAR/SAR interferometry, Light Detection and Ranging (LIDAR), and conventional surveying techniques like., GPS, leveling, etc. These techniques can be compared considering four aspects (i.e., price, accuracy, sampling density, pre-processing requirements). Each technique has its exclusive advantages but also some disadvantages; for a comprehensive review, see (Hengl and Reuter, 2008). However, four main steps are encountered during the generation process of each DEM, regardless of which technology is used (Li et al.,2006): (i) data acquisition (source of elevation data); (ii) resampling to required grid spacing (i.e., regular spaced grid); (iii) interpolation to extract height of required point (i.e., in between two grid cell centers) and (iv) DEM representation, editing, and accuracy assessment. All of these steps mentioned above can introduce errors to the final DEM.

DEMs can be derived from a wide variety of sources. Historically, surveying techniques involving basic tools such as leveling and triangulation were used to generate DEMs. This was followed by photogrammetric techniques involving multiple stereos paired aerial photos.

Techniques for DEM validation have been widely investigated. Gonga-Saholiariliva et al., 2011 gave an overview and mentioned various papers related to DEM validation. An approach of investigation uses the terms of internal and external validation depending on whether or not independent reference data are included in the assessment procedure (Kasser and Yves. ,2001). Another way, often applied, is to group methods of DEM accuracy assessment into quantitative, based on statistics and accuracy measures, and qualitatively based on visual analysis. Those studies covered different continental areas, but not the Adama Town of Ethiopia. Therefore, This study was undertaken to assess the vertical accuracy of ASTER GDEM2, SRTM30m and ALOS (AW3D30) by comparing them to Global Navigation Satellite System (GNSS) validation points over Adama Town 


\section{Previous Work}

DEMs are typically used to represent terrain relief and are particularly relevant for many applications such as soil erosion volume calculations, flood estimates, quantification of earth materials to be moved for channels, roads, dams, embankment, etc. DEM is a general term that represents a continuous surface representation, mainly referred to as a raster. However, in practice, this general term is divided into two main categories. Digital Terrain Model (DTM): which represents the bare ground surface without any natural or man-made structure on tops of it such as trees or buildings; and Digital Surface Model, represents an earth surface that combines the ground surface and the top of all-natural and man-made features (Wassim, 2016).

\subsection{Source of Errors in Digital Elevation Model}

DEM errors occur in vertical directions. Errors propagate from the input data used in creating a DEM right through to calculating surface derivatives and using DEMs in complex applications (Hutchinson and Gallant, 2000; Fisher and Tate, 2006).

Wise (2000) categorized DEM errors as systematic, blunders, or random. These types of errors derive from: (a) deficient spatial sampling and/or the age of data; (b) processing errors such as interpolation or numerical errors; (c) measurement errors from poor positional inaccuracy, faulty equipment, or observer bias (Wechsler, 2007).

\subsection{Shuttle Radar Topography Mission (SRTM)}

Shuttle Radar Topography Mission) acquired DEMs in February 2000 by single-pass SAR interferometry in the C- and X-bands (Farr et al., 2007). According to its mission objectives, SRTM DEMs are expected to have linear vertical absolute height error of less than $16 \mathrm{~m}$, linear vertical relative height error of less than $10 \mathrm{~m}$, circular absolute geo-location error of less than $20 \mathrm{~m}$, and circular relative geo-location error of less than $15 \mathrm{~m}$ (Farr et al., 2007).

\subsection{Advanced Spaceborne Thermal Emission and Reflection Radiometer (ASTER GDEM2)}

It covers the landmasses between $83^{\circ} \mathrm{N}$ and $83^{\circ} \mathrm{S}$ at $\sim 30 \mathrm{~m}$ grid spacing, with some small holes. The accuracy ( $95 \%$ confidence) is $20 \mathrm{~m}$.

The ASTER GDEM v2 contains significant improvements of Version 1 (released in 2009) in terms of spatial coverage, refined horizontal resolution, increased horizontal and vertical accuracy, water masking, and inclusion of new ASTER data to supplement the voids and artifacts (NASA JPL, 2011).

The ALOS (AW3D30) was released in 2015 by the Japan Aerospace Exploration Agency (JAXA). The AW3D-30 is actually a resampling of the 5-meter mesh version of the World 3D Topographic Data, which is considered to be the most precise global-scale elevation data at this time (JAXA, 2015). AW3D30 was generated using the traditional optical stereo matching technique as applied to images acquired by the Panchromatic Remotesensing Instrument for Stereo Mapping (PRISM) sensor onboard the Advanced Land Observing Satellite (ALOS).

\section{Methodology}

\subsection{Data source}

The three Open sources global DEMs and reference datasets used for this study are clearly discussed as follows.

TABLE 1: Data Source and their characteristics details

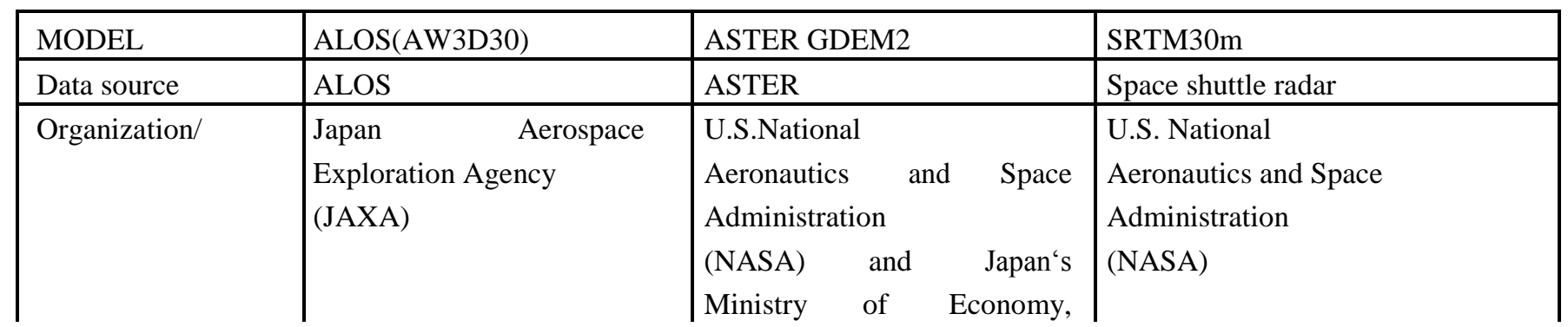




\begin{tabular}{|c|c|c|c|c|c|c|}
\hline & & & & & $\begin{array}{l}\text { Trade, andIndustry(MET } \\
\text { I) }\end{array}$ & \\
\hline \multicolumn{2}{|c|}{ DEM Coverage } & \multicolumn{3}{|c|}{$\begin{array}{l}82^{\circ} \mathrm{N}-82^{\circ} \mathrm{S}, 180^{\circ} \mathrm{E}- \\
180^{\circ} \mathrm{W}\end{array}$} & $\begin{array}{l}83^{\circ} \mathrm{N}-83^{\circ} \mathrm{S}, 180^{\circ} \mathrm{E}-180^{\circ} \\
\mathrm{W}\end{array}$ & $60^{\circ} \mathrm{N}-56^{\circ} \mathrm{S}, 180^{\circ} \mathrm{E}-180^{\circ} \mathrm{W}$ \\
\hline \multicolumn{2}{|c|}{$\begin{array}{l}\text { Acquisition } \\
\text { technique }\end{array}$} & \multicolumn{3}{|c|}{ Optical } & $\begin{array}{l}\text { Satellite stereo } \\
\text { Images }\end{array}$ & $\begin{array}{l}\text { SAR Interferometry } \\
\text { (InSAR) }\end{array}$ \\
\hline \multicolumn{2}{|c|}{ Format } & \multicolumn{3}{|c|}{ GeoTIFF } & GeoTIFF & GeoTIFF \\
\hline \multicolumn{2}{|c|}{$\begin{array}{l}\text { Projection } \\
\text { system }\end{array}$} & \multicolumn{3}{|c|}{ Geographic } & Geographic & Geographic \\
\hline \multicolumn{2}{|c|}{$\begin{array}{l}\text { Horizontal } \\
\text { datum }\end{array}$} & \multicolumn{3}{|c|}{ WGS84 } & WGS84 & WGS84 \\
\hline \multicolumn{2}{|c|}{ Vertical datum } & \multicolumn{3}{|c|}{ EGM96/Orthometric } & EGM96/ Orthometric & EGM96/ Orthometric \\
\hline \multicolumn{2}{|c|}{ Vertical units } & \multicolumn{3}{|c|}{ Meter } & Meter & Meter \\
\hline \multicolumn{2}{|c|}{ Resolution } & \multicolumn{3}{|c|}{$1^{‘ ‘(}(\approx 30 \mathrm{~m})$} & $1^{\prime \prime \prime}(\approx 30 \mathrm{~m})$ & $1^{\prime \prime}(\approx 30 \mathrm{~m})$ \\
\hline \multicolumn{2}{|c|}{$\begin{array}{l}\text { Product } \\
\text { specification } \\
\text { vertical } \\
\text { accuracy(RMSE } \\
\text { ) }\end{array}$} & \multicolumn{3}{|c|}{ $\pm 5 \mathrm{~m}$} & $\pm 17 \mathrm{~m}$ & $\pm 16 \mathrm{~m}$ \\
\hline \multicolumn{2}{|c|}{ Website } & \multicolumn{2}{|c|}{$\begin{array}{l}\text { http://www.eorc.jaxa.jp } \\
\text { /ALOS/en/aw3d30/ }\end{array}$} & & https://lpdaac.usgs.gov/ & https://lpdaac.usgs.gov/ \\
\hline \multicolumn{7}{|c|}{ Reference Datasets } \\
\hline \multicolumn{2}{|l|}{ Data } & \multicolumn{3}{|c|}{ Source } & Number of GCP & Datum Hor/ver. \\
\hline \multicolumn{2}{|c|}{ Adama GCP } & \multicolumn{3}{|c|}{ E.G.I.A } & 158 & UTM Adindan 37N/ m. s.l \\
\hline \multicolumn{2}{|c|}{ Digital contour } & \multicolumn{3}{|c|}{ E.G.I.A } & 2-meter contour interval & UTM Adindan 37N/ m.s.l \\
\hline \multicolumn{7}{|c|}{ Software } \\
\hline No & Name & & $\begin{array}{l}\text { Versio } \\
\mathrm{n}\end{array}$ & \multicolumn{3}{|c|}{ Purpose } \\
\hline 1 & \multicolumn{2}{|c|}{ ArcGIS software } & 10.4 & \multicolumn{3}{|c|}{$\begin{array}{l}\text { For mosaicking tiles, clip the relevant portion, and extracting } \\
\text { elevation values of points. } \\
\text { To create reference DEM }\end{array}$} \\
\hline 2 & \multicolumn{2}{|c|}{$\begin{array}{l}\text { Global Mapper } \\
\text { software }\end{array}$} & 2019 & For & coordinate transformation & \\
\hline 3 & Microsoft & & 2013 & For & the statistical analysis & \\
\hline
\end{tabular}

\subsection{Data Processing and Analysis Method}

Open source global DEMs (ALOS, ASTER GDEM2, and SRTM) DEMs are open access and downloaded from their respective online portals. The transformation of all the data sets into a common system using ArcGIS 10.4 and Global mapper ver.19 software. To transform the measured WGS84 coordinate system to the local projection system. Table 3.2 shows the transformation parameters, as published by the E.G.I.A, used for the conversion

The first three are the translation parameters between the two systems, the following $\mathrm{Rx}, \mathrm{Ry}$, and $\mathrm{Rz}$ are the rotation parameters of the X, Y, and Z axes from the reference WGS84 to the local system and the scale factor is expressed in parts per million.

TABLE 2: Transformation parameters from WGS84 to the local system, Adindan UTM. 


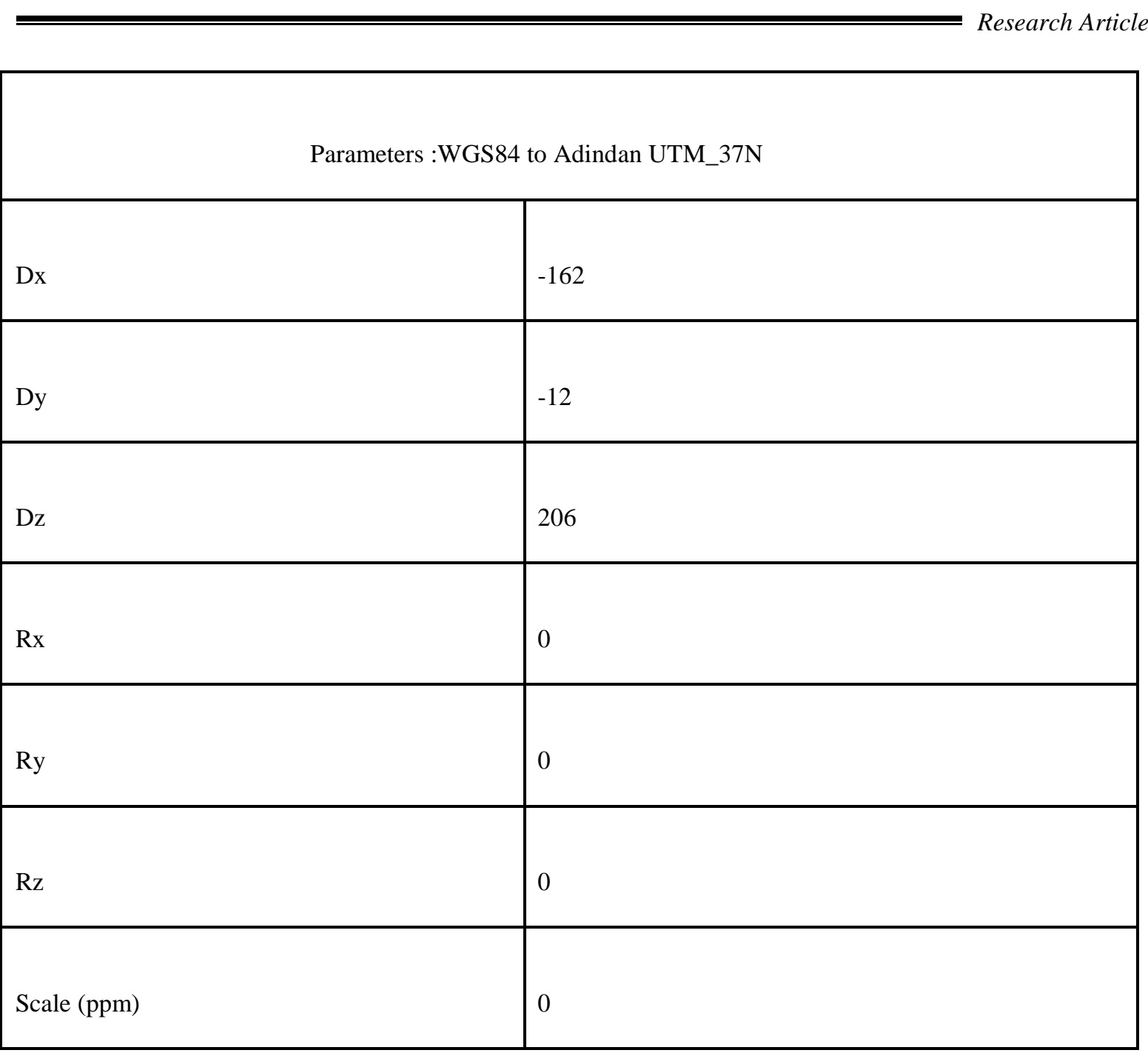

Source: Ethiopia Geospatial Institute Agency

\subsection{Reference DEM Preparation}

The reference DEM used for this study is produced from digital contour line data using _ArcGIS 10.4's Topo to raster tool'. Topo to raster tool is an interpolation method specifically designed for the creation of hydrologically correct DEMs(Hutchinson et al., 2011). This method uses an iterative finite-difference interpolation technique. It is optimized to have the computational efficiency of local interpolation methods such as Inverse Distance Weighted (IDW) without losing the surface continuity of the global interpolation methods such as kriging and spline(ESRI 2016).

The accuracy of Reference DEM was validated by using 100 ground control points collected DGPS for cadastral mapping purpose of cross Adama Town. According to the validation result of the reference, DEM has an accuracy of 1.2 meters. The closer the value of the RMSE to zero, the dataset is more accurate (Apeh et al., 2019). This DEM is assumed to be accurate and covering about $313 \mathrm{sq} . \mathrm{km}$ in the total area of the study area.

\subsection{Visual analysis}

Visual analysis is another accuracy evaluation method based on the comparison of DEM derived surface that is generated from DEM and different application that uses DEM with same products generated from higher standard DEM. To perform the DEM accuracy test in this method.

Shaded relief maps in both reference and open access DEMs were compared. 
Research Article

$\square \quad$ The slope was derived from SRTM, ALOS, and ASTER DEMs and Reference DEMs and compared through visual inspection. Accuracy of these DEMs concerning terrain slope was analyzed

$\square \quad$ Drainage network extracted from SRTM, ALOS and ASTER DEMs were compared with same product of Reference DEM for same

Drainage networks can give some information about DEMs quality such as whether these DEMs could capture the general topographic features of the study areas (Sertel 2010). All derivative analysis carried out by ArcGis 10.4 software analysis toolset.

Vertical Accuracy at 95\% Confidence Level $=1.9600 *$ RMSE.

Maune et al., 2001 accuracy is the closeness of observation to a true value . The value of the RMSE closer to zero, means the heights obtained from DEMs are more accurate while the value of the RMSE far from zero, the heights obtained from DEMs are less accurate (Apeh et al., 2019) and Chirico et al., 2012).

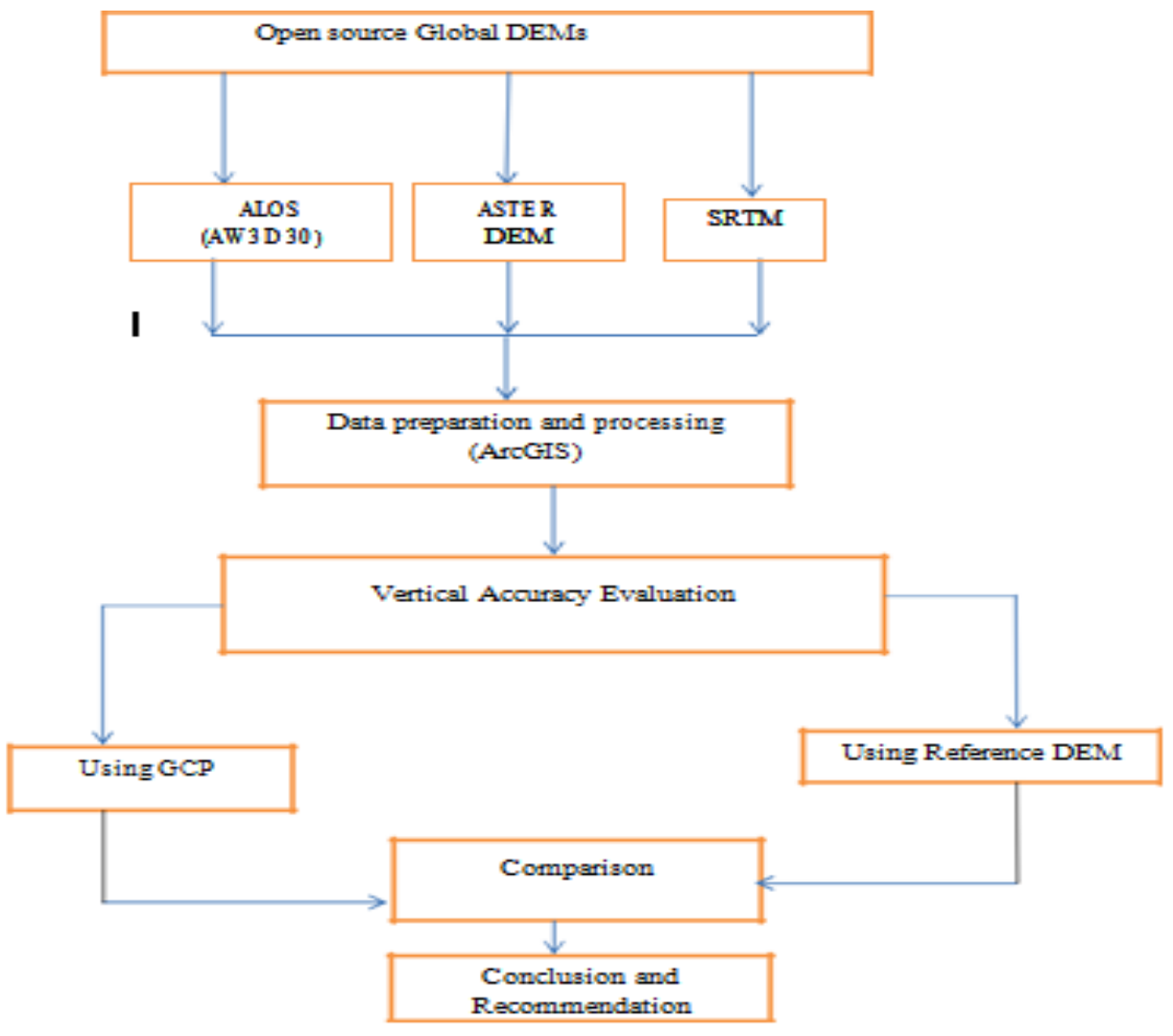

Figure 1 Technological Scheme Methodology

\section{Results and Discussion}

\section{A. Accuracy Assessment of DEMs Using DGPS Ground Control Points}

To determine the accuracy of the ALOS, SRTM, and ASTER DEMs ground control points surveyed by GNSS instrument used as reference data with a high accuracy . One hounded fifty-eight (158) Differential Ground surveyed control points are available being well distributed in the study area . Elevation values (Z)of ASTER, SRTM, and ALOS (here after called Z-ASTER, Z-SRTM, and Z-ALOS) are extracted from the corresponding DEM pixel for each point using Spatial Analyst Tools of Arc GIS software (i.e. Extract Value to point). The elevation values of DEMs (i.e. Z-ASTER, Z-SRTM, and Z-ALOS) were subtracted from the corresponding GPS surveyed point's elevation values (ZGPS) to calculate the error (using equation 3.1 through 3.6). Statistical parameters are minimum error, maximum error, mean error, and standard deviation of the elevation difference 
between GPS elevation points and DEMs were calculated. Finally, DEM accuracy is assessed by calculating vertical RMSE. The RMSE statistics are essentially a standard deviation and are thus based on the assumption that errors in the DEM are random and normally distributed. For Adama, the RMSE values are 11.18m, 4.63m, and 5.25m for ASTER, SRTM, and ALOS DEMs respectively.

TABLE-3: $\quad$ Statistics analysis of elevation difference between GCP points and ASTER, SRTM and ALOS DEM

\begin{tabular}{|l|l|l|l|}
\hline \multirow{2}{*}{ Statistical parameters } & \multicolumn{3}{|c|}{ Statistics analysis of DEMs } \\
\cline { 2 - 4 } & SRTM 30 & $\begin{array}{l}\text { ASTER } \\
\text { GDEM2 }\end{array}$ & ALOS \\
\hline Count & 158 & 158 & 158 \\
\hline Minimum(m) & -20.78 & -17.78 & -3.77 \\
\hline Maximum(m) & 16.65 & 38.79 & 14.62 \\
\hline Mean error(m) & -1.9 & 8.16 & 4.09 \\
\hline Standard Deviation(m) & 4.23 & 7.67 & 3.30 \\
\hline Kurtosis & 5.2 & 3.09 & 0.24 \\
\hline Skew & -0.2 & 1.25 & 0.22 \\
\hline RMSE $(\mathrm{m})$ & \pm 4.63 & \pm 11.18 & \pm 5.25 \\
\hline Accuracy $(95 \%)$ & $9.1 \mathrm{~m}$ & $21.91 \mathrm{~m}$ & $10.29 \mathrm{~m}$ \\
\hline
\end{tabular}

The vertical accuracy evaluation of the three DEMs reveals that the SRTM data has smaller RMSE was obtained for SRTM than AW3D30, ASTER GDEM2. So, SRTM is a better vertical accuracy than both ASTER GDEM2 and ALOS for the study area. The vertical accuracy of ASTER GDEM2 is less accurate than the accuracy of ALOS and SRTM, as it achieved a much higher RMSE compared to ALOS and SRTM. The better accuracy of SRTM over ASTER has been noted in previous studies(Chaieb et al.,2016 ; Abdi (2018) ; Hanafy et al., 2017 and Yap et al.,2018).

Elevation difference histograms were drawn for investigating the error distribution behavior of these three DEMs. The relative frequency distribution of the height differencesbetween reference (GPS) data and examined DEMs are provided in the figure below.

However, the histograms of elevation differences shows positive or negative skew for these DEMs which indicate that the examined DEMs are underestimates or overestimate the terrain elevation of study area.

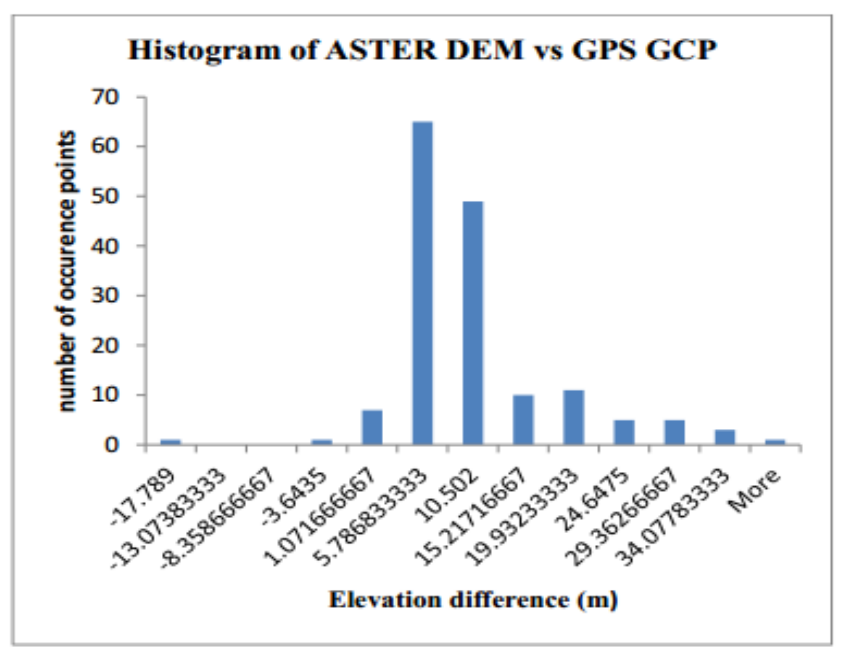

Figure -2 : Histogram of ASTER and GCP Elevation Differences 


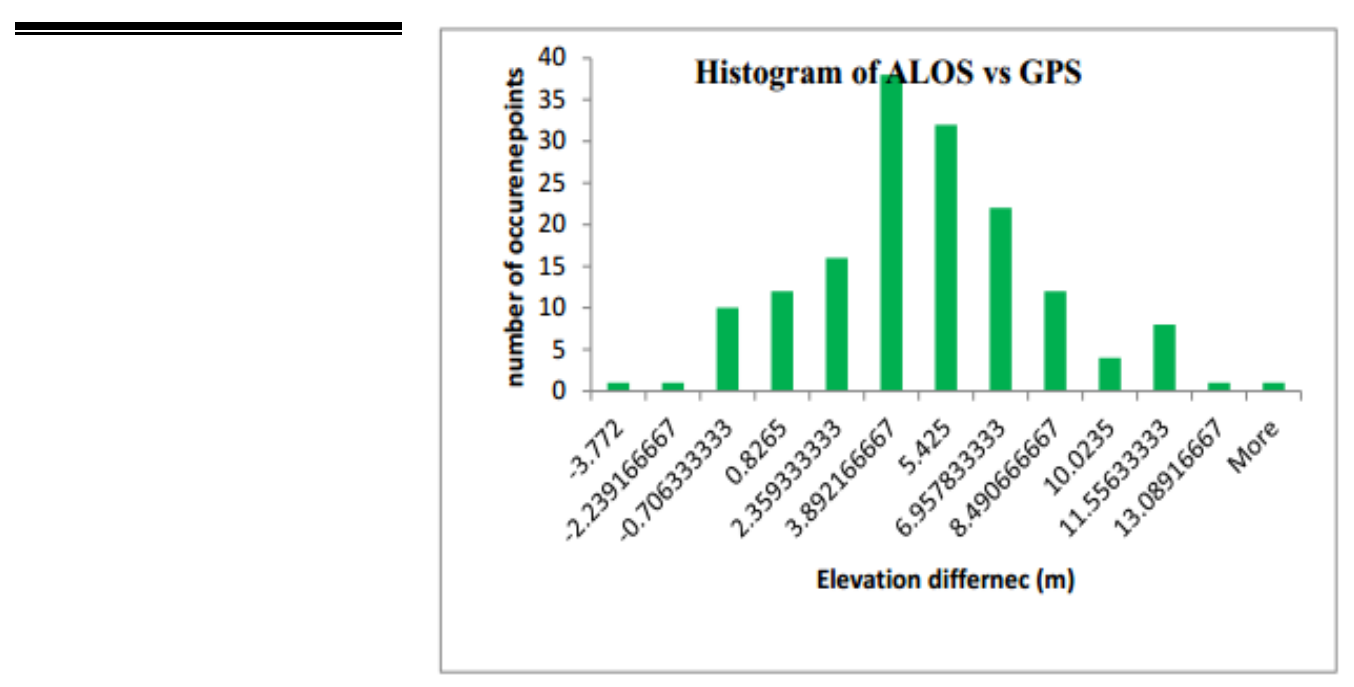

arch Article

Figure -3: Histogram of ALOS and GPS GCP elevation Differences

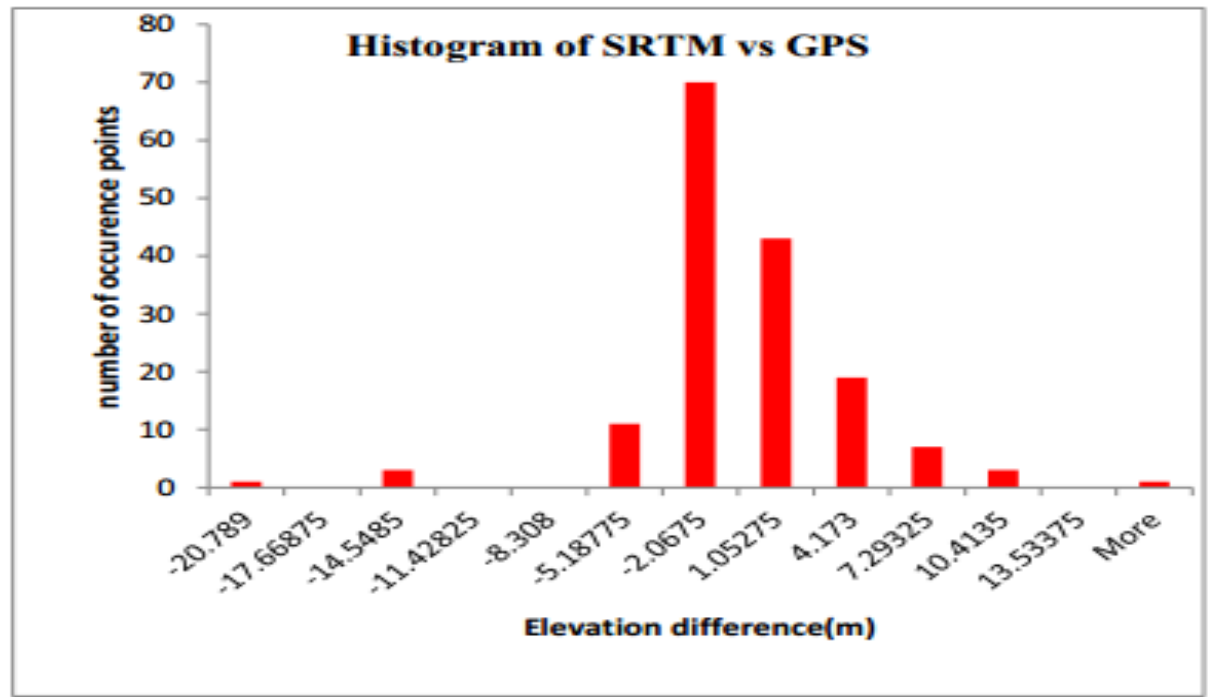

Figure -4 : Histogram of SRTM and GPS GCP of elevation differences

The histogram of elevation difference figure (4.3) presents a negative, indicating that the SRTM model overestimates the spatial distribution of terrain elevation. The histogram Figures (4.1) present frequencies of positive errors greater than those of the negative errors. A large positive bias is clearly observed in figure (4.1) indicating that the ASTER underestimated the terrain elevation.

In the graphs, ASTER elevation differences with GPS elevations have mainly positive values. This shows ASTER GDEM has under estimated the topography of the area which means that ASTER GDEM elevation values are below to GCPs elevation values. SRTM and ALOS elevation differences with GPS elevation are mainly negative. This shows SRTM and ALOS DEMs have a moderate overestimation of the study area topography (i.e SRTM and ALOS elevation values are above to GCPs elevation values).

\section{B. Correlation and Regression Analysis of variation in elevation}

Whereas $R^{2}$ determines the percentage of variation in the values of errors in this study. $R^{2}$ is known as coefficient of determination and its value is 0 to 1 


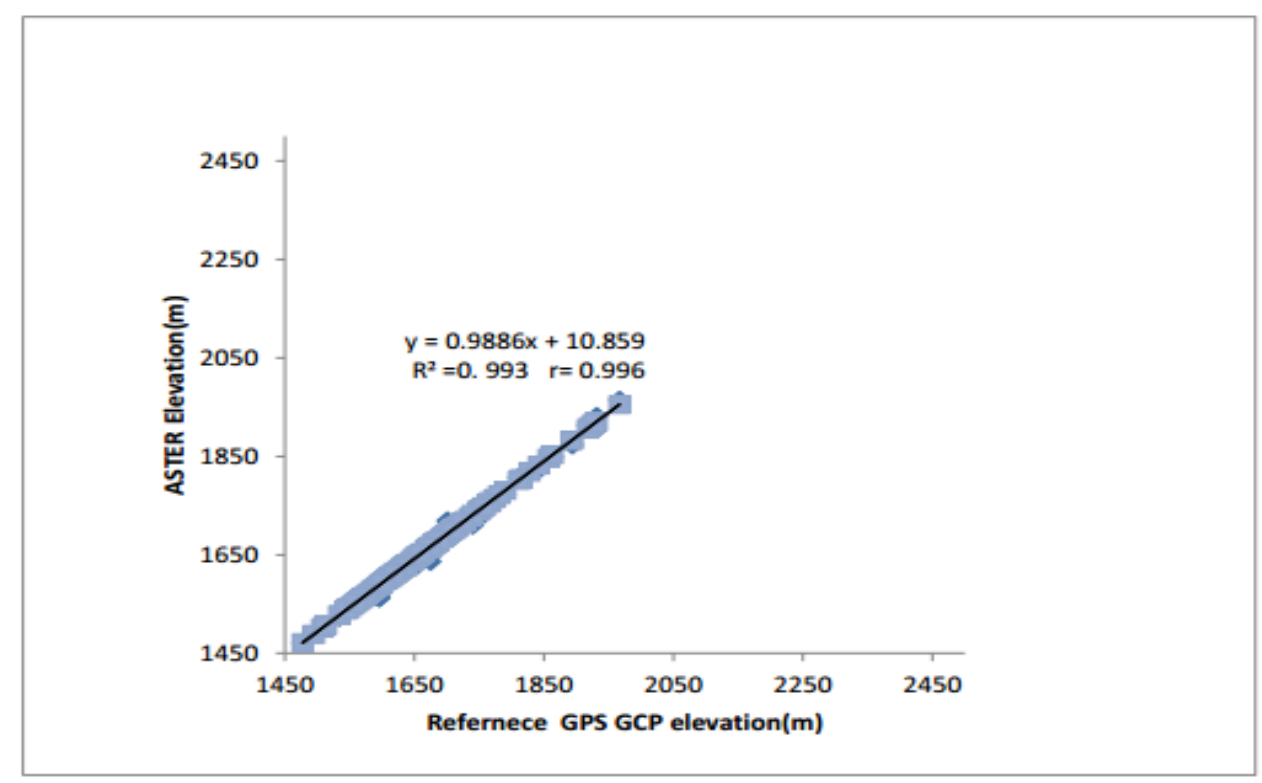

Figure-5: Correlation between ASTER elevation(m) and GPS Elevation (m)

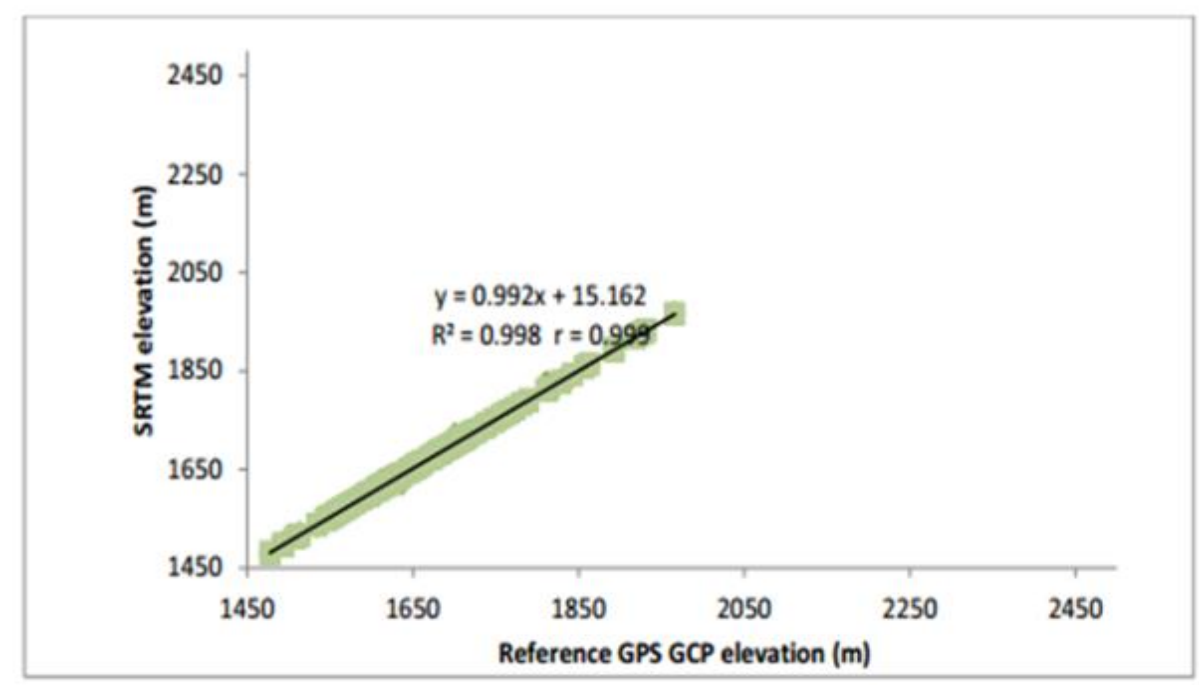

Figure - 6 : Correlation between SRTM elevation(m) and GPS elevation(m)

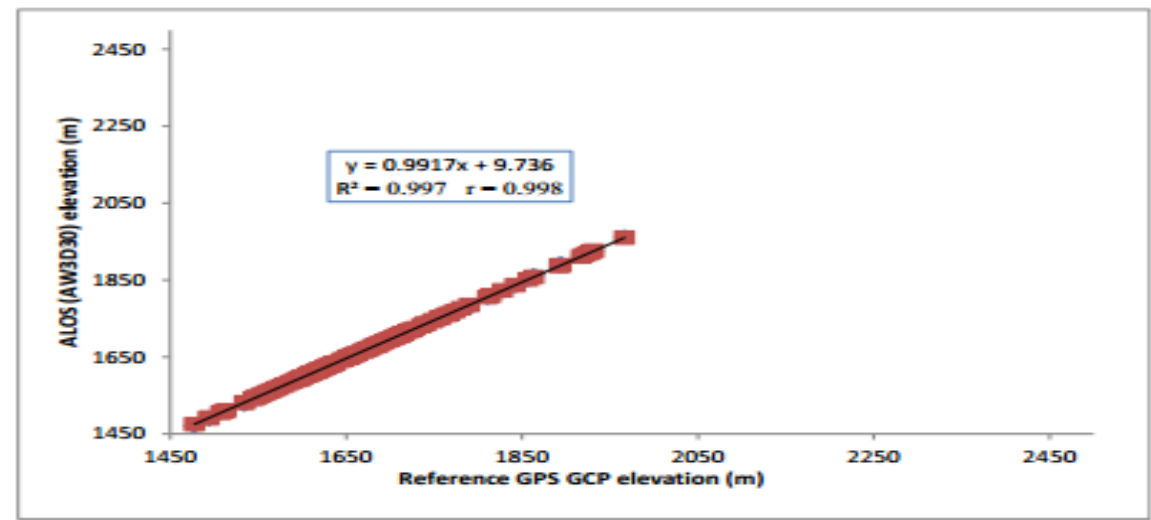

Figure-7: Correlation between ALOS(AW3D30) elevation(m) and GPS elevation(m) 
The deterministic model $\left(\mathrm{R}^{2}\right)$ and the correlation coefficients ( $\mathrm{r}$ ) between the variables were calculated and the results are shown in Table 4.2 below respectively.

TABLE - 4: $\mathbf{R}^{2}$ and $\mathbf{r}$ Statistic Computed

\begin{tabular}{|l|l|l|}
\hline Scatter plots & $\mathrm{R} 2$ & $\mathrm{r}$ \\
\hline Aster Elevation (m) & 0.993 & 0.996 \\
against GPS Elevation (m) & & \\
\hline SRTM Elevation (m) & 0.998 & 0.999 \\
against GPS Elevation (m & & \\
\hline ALOS Elevation (m) & 0.997 & 0.998 \\
\hline against GPS Elevation (m & & \\
\hline
\end{tabular}

The values of $\mathrm{R}^{2}$ (Table 4.2) help to interpret the relationships existing between the variables (DEMs and GPS elevation) in terms of variations. These $\mathrm{R}^{2}$ values indicate that $99.8 \%, 99.3 \%$, and $99.7 \%$ of the changes in SRTM, ASTER, and ALOS elevation are explained by the change of GPS elevation. The closer $\mathrm{R}^{2}$ is to 1 , then there is an indication that the data points lie close to the least square line. This can be seen in the Figures above. Concerning Table 4.2, it can be seen that the $\mathrm{R}^{2}$ value for SRTM is relatively closer to 1 . This means that the linear regression analysis performed to estimate the $\mathrm{R}^{2}$, comparatively, describes the variation in the data with reliable accuracy for Adama. In this study, the correlation coefficient ( $r$ ) was used as a criterion to determine the strength and nature of the linear relationship between the three DEMs (ASTER, ALOS, and SRTM) and the referenced GPS elevation.

In the analysis, the value of $\mathrm{R}^{2}$ is highest in SRTM DEM among three open-source global DEMs. SRTM has a maximum value which indicates the best correlation of elevation of GPS GCP from among all three DEMs. SRTM has better values of $\mathrm{R}^{2}$ than ALOS and ASTER .problem of investigated DEMs particularly in peak and high elevation area. All derivative analysis was carried out by ArcGIS10.4 software 3D analysis toolset.

\section{Accuracy Assessment using DEM Derivative Analysis}

DEM accuracy has been evaluated by comparison of derived DEM products namely-slope and drainage network, with same products derived from Reference DEM, prepared for the purpose of this present study. Visual interpretation of derived surface like shaded relief map can give some information about DEMs quality DEM such as whether these DEMs could capture the general topographic features of the study area (Sertel, 2010). Comparing the produced shaded relief map with that of reference DEM clearly shows the 


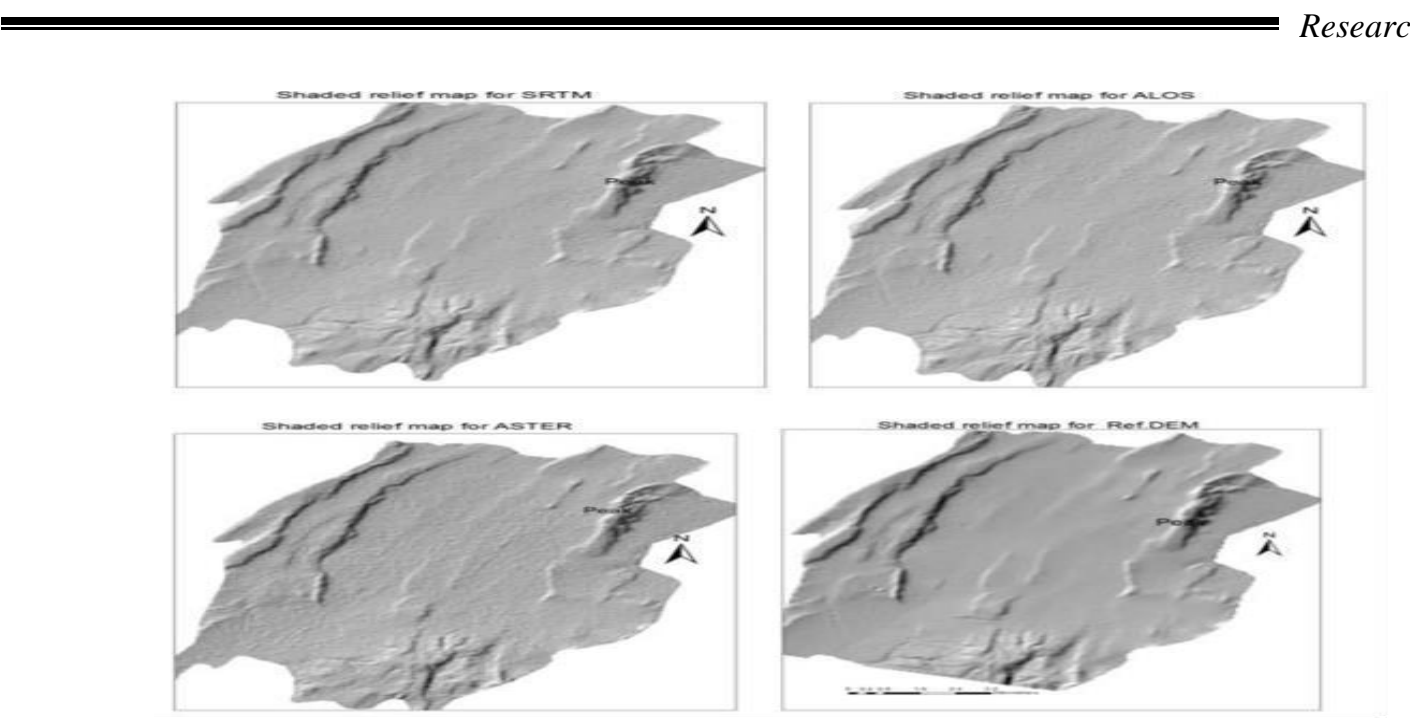

Figure -8: Shaded relief maps for: SRTM, ALOS, Ref.DEM and ASTER DEMs of

Adama study area

\section{Slope and DEM Accuracy}

Slope of terrain topography is a major influencing factor for the vertical accuracy of DEM (Imrani, et al., 2016 and Abdi, 2018 ). As terrain slope affects the accuracy of DEMs, its quality is also affected by the quality of its source, one of which is DEMs. To do all DEMs are classified into nine (9) slope surface was derived from each DEM. All these processes were performed in an ArcGIS software environment using 3D and spatial analyst toolsets. As Figure 4-8 shows slope derived from SRTM DEM is better than those derived from ALOS and ASTER DEMs as compared to reference DEM for this study area. Slope extracted from ASTER DEM reveals the rough accuracy of the dataset. As the figure below shows the red color that represents rugged slope is distributed over the low land areas in the slope map extracted from ASTER DEM. On the other hand, the SRTM slope map is more similar to that of Reference DEM. The average slopes of the Town could be taken as $4 \%$. The major proportion, more than $75 \%$ of the City, can be represented between 1 to $10 \%$ slopes. The visual analysis of the investigated DEMs indicates that the SRTM 30(Figure below) is the most similar to the reference DEM.
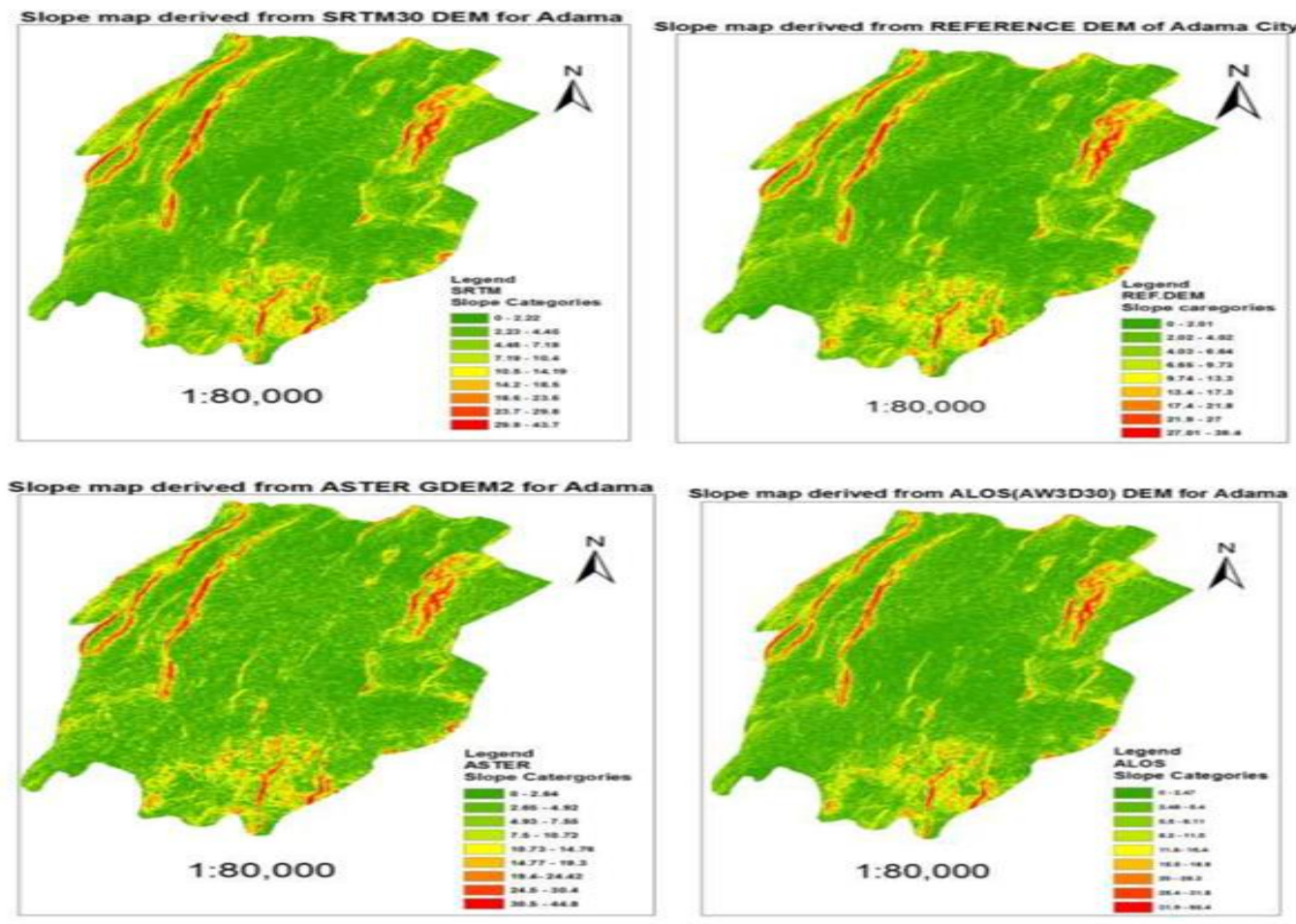

Figure-9: Slope maps derived from,Upper left- SRTM DEM ,Upper right- Ref. DEM, lower left-ASTER DEM and lower right- ALOS of Adama 


\section{E. Accuracy Assessment by Comparison of Derived Drainage Network}

Multiple tools are available which are specialized for the derivation of watersheds and drainages networks, including Arc hydro and Arc SWAT (ESRI, 2016). These tools use DEM as input and can perform watershed and drainage network extraction in an automated manner for hydrological modeling.

However, in this study drainage network extraction was performed through the hydrologic modeling tools in the ArcGIS Spatial Analyst extension toolbox. To automate the process and integrate with other ArcGIS tools such as Raster Calculator, a model tool was created in Arc Map's Model Builder window, which helped to simplify workflows by string together sequences of tools, feeding the output of one tool into another tool as input

Drainage extraction in ArcGIS model tool that was used to assess the relative accuracy of the three DEMs. The stream network from the three DEMs, namely ASTER, SRTM, and ALOS(AW3D30) was first visually compared (as in the figure below) with stream network derived from reference DEM for the study area. Then, stream length and numbers (count) at 5 different stream orders was compared with that of reference stream network data in study area

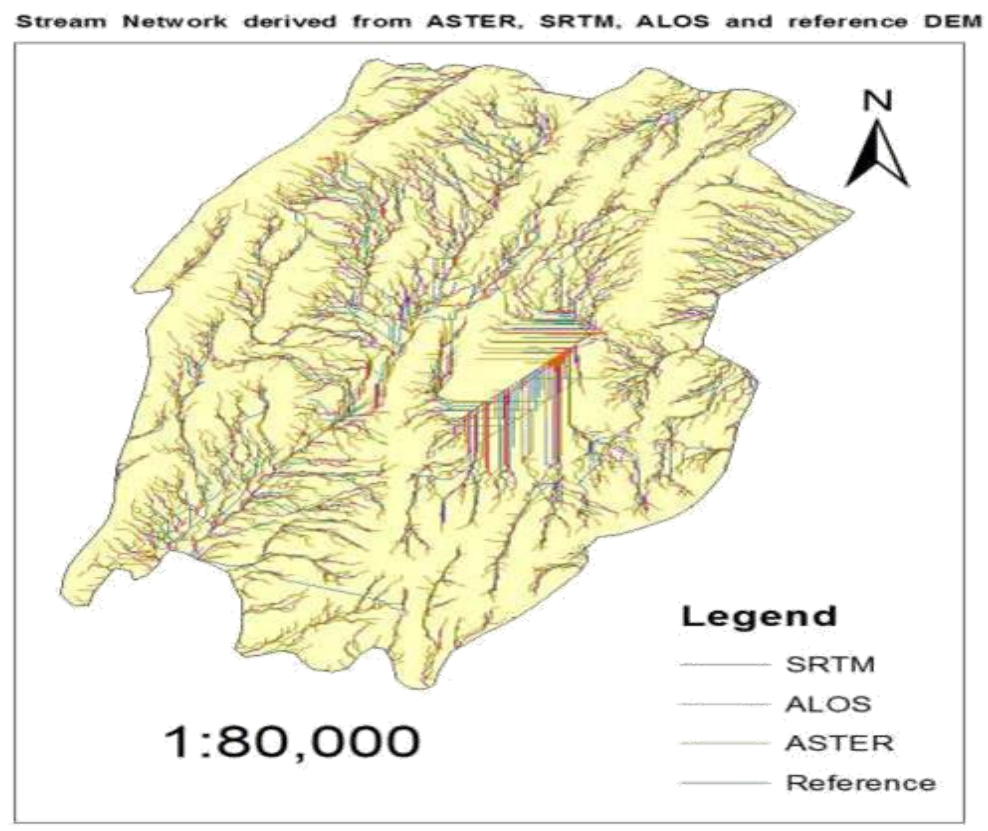

Figure -10: Stream Network derived from ASTER, SRTM, ALOS and reference DEM for Adama

SRTM stream network is more accurately produced than ASTER and ALOS DEMs when compared concerning Ref. DEM derived stream networks. When compared by stream length and order (Table 4-3), SRTM derived stream network the highest first-order stream but the lowest higher-order streamlines. The total length of first-order streamlines is $233.4 \mathrm{~km}$ for SRAM, $225.5 \mathrm{~km}$ for ALOS, $223.05 \mathrm{~km}$ for ASTER, and $241.83 \mathrm{~km}$ for Ref. DEM respectively in Adama.

TABLE-5: Stream length differences $(\mathrm{km})$ for 5 stream orders derived from SRTM ALOS ASTER and Reference DEM Adama

\begin{tabular}{|c|c|c|c|c|c|c|c|c|c|c|c|}
\hline \multirow{2}{*}{$\begin{array}{c}\text { Stream } \\
\mathrm{m} \\
\text { order }\end{array}$} & \multicolumn{2}{|l|}{ Reference DEM } & \multicolumn{3}{|c|}{ SRTM } & \multicolumn{3}{|c|}{ ALOS } & \multicolumn{3}{c|}{ ASTER } \\
\hline 1 & Count & Length & Count & Length & Diff. & Count & Length & Diff & Count & Length & Diff \\
\hline 2 & 3678 & 241.83 & 6446 & 233.43 & $\mathbf{8 . 4}$ & 6226 & 225.46 & $\mathbf{1 6 . 3}$ & 6192 & 223.05 & $\mathbf{1 8 . 8}$ \\
\hline 3 & 1564 & 54.08 & 1575 & 54.46 & $\mathbf{- 0 . 3 8}$ & 1678 & 58.02 & $\mathbf{- 3 . 9}$ & 1577 & 55.2 & $\mathbf{- 1 . 1}$ \\
\hline 4 & 346 & 12.62 & 380 & 13.86 & $\mathbf{- 1 . 2 4}$ & 432 & 15.75 & $\mathbf{- 2 . 7}$ & 449 & 15.3 & $\mathbf{- 2 . 3}$ \\
\hline 5 & 283 & 10.04 & 276 & 9.8 & $\mathbf{0 . 2 4}$ & 297 & 10.54 & $\mathbf{- 0 . 5}$ & 287 & 10.4 & $\mathbf{- 0 . 3 6}$
\end{tabular}




\begin{tabular}{|c|c|c|c|c|c|c|c|c|c|c|c|} 
& & & & & & & & & \\
\hline Total & 12036 & 430.16 & 11844 & 421.12 & $\mathbf{8 . 7 2}$ & 12278 & 417.57 & $\mathbf{1 2 . 6}$ & 11672 & 414.9 & $\mathbf{1 5 . 4}$ \\
\hline
\end{tabular}

As table 4-3 shows the stream network derived from SRTM DEM is better than the reference Stream networks. ASTER has the highest difference $(15.4 \mathrm{~km})$ in total.

\section{F. Discussion}

This section discusses the result found by this particular study for the study area. The study investigated the accuracy of three global and open-source DEMs: ASTER GDEM2, ALOS (AW3D30), and SRTM 30m DEMs by using DGPS and supplementary topographic data as a reference DEM data. For the present study, GPS points were used to evaluate the accuracy of three DEMs (ASTER, SRTM, and ALOS). The elevation difference values of these DEMs were extracted for the location of GPS points and subtracted from these GPS points elevation values.

Table 4.1 shows the summary statistics for elevation errors of ASTER-GDEM ver.2, SRTM 30, and ALOS elevation errors over the study area. The RMSE for SRTM is $4.63 \mathrm{~m}$ and that of ALOS is $5.25 \mathrm{~m}$, ASTER is $11.18 \mathrm{~m}$ and thus, their vertical accuracy (RMSE* 1.96) is $9.1 \mathrm{~m} 10.29 \mathrm{~m}$, and $21.9 \mathrm{~m}$ respectively. The accuracy of SRTM is better than ALSO and ASTER, which has been marked in previous studies. SRTM gives better accuracy and those results were concluded (Table 2.1) that were mentioned by (Chaieb et al., 2016 and Abdi, 2018). It shows that the DEMs on vertical precision depend on location, errors of reference point, terrain characteristics, and surface properties. Hence, this recommendation performs to an investigation into those factors. Besides, Table 4.1 explains that the RMSE value of $11.18 \mathrm{~m}$ for ASTER GDEM2 are very similar to those described by Chaieb et al.2016. According to the open-source global DEMs evaluation, this study reports that the ASTER GDEM2 is lower accurate to compare with SRTM 30m and ALOS (AW3D30) for the same resolution. In general, the Accuracy of SRTM is better than that concluded in the literature review which has been marked in previous studies (Yap et al., 2018; Ouerghi et al., 2015) and officially stated vertical accuracy of $\pm 16 \mathrm{~m}$ at $95 \%$ confidence in the SRTM data mission specification.

The histograms of the differences between DEMs and the reference DEM data (Figure4.1- 4.3) are closely following a normal distribution. However, for the SRTM difference histogram present a negative error of -2.06 which is illustrated in the histograms (Figure (4.3)) with negative error observed, indicating that the SRTM Elevation Modem of negative errors greater than those of the positive errors (overestimated the terrain elevation). The histograms of elevation differences (Figure 4.1) present slightly positive errors, indicating a clear positive bias for ASTER concerning reference elevation data, where the ASTER model underestimates the spatial distribution of terrain elevation, this underestimation of ASTER was noted in previous studies (Hirt et al., 2010; Li et al., 2013).

The second accuracy assessment test was carried out by using local DEM as reference Datasets. The DEM used in this study area as reference DEM has an accuracy of $1.2 \mathrm{~m}$ (at $95 \%$ confidence interval). Shaded relief maps produced from ASTER, SRTM, and ALOS DEMs show that SRTM is better at representing the relief of the study area. The visual analysis of the investigated DEMs indicates that the SRTM 30(Fig. 4.8) is the most similar to the reference DEM. On the other hand, ASTER GDEM produced stream networks that have the highest deviation from the reference stream networks. In general, SRTM 30 DEM has shown better quality in derivatives surface quality than the other two DEM and closely followed by ALOS (AW3D30) DEM dataset, and ASTER has the least accuracy of the three DEMs evaluated in this research for this study area. Current research is the first study to investigate the accuracy of freely available DEMs ALOS, ASTER, and SRTM for Adama city, Ethiopia. This means that SRTM30 DEM best represents the topography of the earth's surface. From the above discussions SRTM, 30m has a better representative of the topography of Adama city area. ALOS (W3D30m) DEM can also be considered as the best second option, for hydrological modeling applications.

\section{Conclusion}

This study focused on the assessment vertical accuracy of global open source DEMs (ASTER GDEM2, SRTM-30m, and ALOS-AW3D30) of Adama city in Ethiopia by using GCP points measured by DGPS and Reference DEM as reference data. The research used a statistical analysis method to calculate RMSE of elevation differences between these DEMs and GCPs elevation datasets. Their vertical accuracy in comparison with differential GPS ground control points for Adama Town is $\pm 4.63 \mathrm{~m}$ for SRTM, $\pm 11.18 \mathrm{~m}$ for ASTER, and \pm 5.25 $\mathrm{m}$ for ALOS (AW3D30) in terms of their RMSE respectively. The obtained RMSE value for SRTM is smaller 
than AW3D30 and ASTER GDEM. The vertical accuracy of SRTM30m is more accurate than ALOS and ASTER in Adama city, because it contains the smallest root mean square error. Accuracy of ASTER GDEM2 is less than SRTM and ASTER. The investigation of vertical accuracy of these DEMs by terrain derivatives (slope and drainage networks) has confirmed the under representation of ASTER DEM for the topography of the study area, which can be seen clearly from the histogram of elevation difference for these DEMs. The assessed result indicated that SRTM30m has the better quality to extract slope and drainage network (stream network).

\section{References}

[1] Apeh, O.I., Uzodinma, V.N., Ebinne, E.S., Moka, E.C., and Onah, E.U. (2019). Accuracy Assessment of ALOS W3D30, ASTER GDEM AND SRTM30 DEM: A Case Study of Nigeria, West Africa. Journal of Geographic Information System, 11, pp. 111-123.

[2] Arefi, H., \& P. Reinartz. (2011). Accuracy enhancement of ASTER global digital elevation models using ICESat data. Remote Sensing, 3(7): pp. 1323-1343.

[3] Federal Geographic Data Committee. "Geospatial Positioning Accuracy Standards Part3." Fisher, P.F., and Tate, N.J. (2006). Causes and Consequences of Error in Digital Elevation Models. Progress in Physical Geography, 30, pp. 467-489.

[4] Gong, J.; Li, Z.; Zhu, Q.; Sui, H.; Zhou, Y.( 2000).Effects of various factors on the accuracy of DEMs: An intensive experimental investigation. Photogram. Eng. Remote Sens., 66, pp. 1113-1117.

[5] Gonga-Saholiariliva N, Gunnell Y, Petit C, Mering C. (2011). Techniques for quantifying the accuracy of gridded elevation models and for mapping uncertainty in digital terrain analysis. Prog. Phys. Geogr., 35, pp.739-764.

[6] Habib et al. (2017). Extraction and Accuracy Assessment of High-Resolution DEM and Derived Orthoimages from ALOS- PRISM Data over Sahel-Doukkala (Morocco). Earth Science Informatics, 10, pp.197-217.

[7] Hanafy M. Kamal, Anas M. A. El-Molla, Hany G. Ahmed, Mostafa H.A. Mohamed, Salem S. Saleh. (2017). Accuracy Assessment of SRTM and ASTER DEMs over Egypt. International Journal of Scientific \& Engineering Research, Volume 8, Issue 11,

[8] Hengl, T. and Evans, I. S., (2009) Mathematical and Digital models of the Land Surface. Geomorphometry concepts, software, applications, pp. 31- 63.

[9] Hoffmann-Wellenhof, B, and J. Collins (1994). Global Positioning System: Theory and Practice. New York: Springer-Verlag,

[10] Howell, (2007). - Correlation and regression,\| Stat. methods Psychol., pp. $1 \mathrm{Hu}$, Z.and Hou, Y. (2017)Evaluation of Recently, Released Open Global Digital Elevation Models of Hubei, China. Remote Sens., 9, pp.262.

[11] I.Abdi (2018). vertical accuracy assessment of open source digital elevation model using GPS points reference DEM over Ethiopia a case study in Addis Ababa and Dire Dawa (MSc thesis), AAU, Ethiopia

[12] Kasser, M.and Yves, E. (2001). Digital Photogrammetry; Taylor \& Francis: London, UK, p. 351 Kobrick, M. (2006). How SRTM was born. Photogramm. Eng. Remote Sens., 72, pp.206-210

[13] JAXA (2017) ALOS Global Digital Surface Model —ALOS World 3D-30 m(AW3D30)\| . JAXA,

[14] Lane et al,.(1994), Developments in monitoring and modeling small-scale river bed topography. Earth Surface Processes Landforms, 19, pp. 349-368.

[15] Leica Geosystems. (2012). Leica GS15 GNSS Series: Technical Data; Leica Geosystems AG: Heerbrugg, Switzerland,

[16] Maune, D.F., (2007). Digital Elevation Model Technologies and Applications: The DEM User Manual, 2nd ed.; Asprs Pubns: Bethesda, MD, USA. 
[17] Mukherjee, S., Joshi, P.K., Mukherjee, S., Ghosh, A., Garg, R.D. and Mukhopadhyay, A. (2013) Evaluation of Vertical Accuracy of Open Source Digital Elevation Model (DEM). International Journal of Applied Earth Observation and Geoinformation, 21, pp.205-217.

[18] National Remote sensing Center Indian SpaceResearch organization Dept. of Space, Govt. of India(2014) "Evaluation of Indian National DEM (Version 2) From Cartosat-1 Data." Hyderabad,

[19] NIMA. (2000). World geodetic system 1984: its definition and relationships with local geodetic systems. National Imagery and Mapping Agency technical report No. 8350.2 third edition.

[20] Sertel, E. (2010). Accuracy assessment of ASTER global DEM over Turkey, in : A Special Joint Symposium of ISPRS Technical Commission IV \& AutoCarto in Conjunction with ASPRS/CaGIS 2010 Fall Specialty Conference. Orlando, pp. 15-19.

[21] USGS (2015) Earth Explorer. USGS, Earth Resources Observation and Science Center, Sioux Fall, SD. http://earthexplorer.usgs.gov 